\title{
Patients repeatedly admitted to psychiatric wards: a four-year follow-up
}

\author{
Steffan Davies and Simon Payne
}

\begin{abstract}
Provious studies have looked at repeated acmisstons and falled discharges but nons have followed up a group of potionts requiring multiple admisatons over soveral years. We found that of the 42 patients admilted three or more times to acute wards in 1990, hall were having a bad year and dild not require this lovel of inpatient care in succeseding years; ons-quater continued to use ceuto services heavty but none required three or more actmisetions in every yecr of follow-up; one-quater did bactly and required prolonged in-pallient care or died.
\end{abstract}

Patients who are frequently admitted to psychiatric wards often generate bad feelings and resentment among staff. This is especially so for junior doctors and nursing staff who are required to admit them and seems out of proportion to the resources they consume. There has previously been consideration of the problem of repeated admissions (Evans et al, 1992a,b) and failed discharges (Jones, 1991). There is, however, little information on the long-term prognosis for this group. Do these patients continue to require frequent admissions or are they just having a bad year? Are they at risk of a poor outcome of suicide or prolonged hospitalisation? Do they suffer from major mental llinesses which are difficult to stabilise? do they suffer from personality disorder and/or substance misuse? or does the combination cause their frequent admissions?

The concept of the 'revolving door' patient is not new to British psychiatry. Duncan MacMillan, Physician Superintendent of Mapperley Hospital in the 1950s, regarded the frequent readmission of patients who would previously have had prolonged admissions as the success of his 'open door' policy, one of the earliest community care policies in the United Kingdom. At Mapperley Hospital in 1957, 1310 patients accounted for 1638 admissions. Twenty-nine patients were admitted 3 times, seven 4 times, two 5, one 6 and one 7 (MacMillan, 1958). Although this group of patients has been identified in the literature for many years, there is little information about their longer-term contact with psychiatric services.
Evans (1992) found that the three patients with six or more admissions in her study had had 'a time of illness' before their multiple admissions. They had had a more 'usual' rate of admissions previously and two of them had been stable in the community for lengthy periods following their multiple admissions. Evans' paper was followed by vigorous debate about the part played by substance misuse in the cases quoted (Cohen, 1992, 1993). Jones' (1991) audit of failed discharges (readmissions within three months) found that this group had significantly more admissions overall and was more likely to have patients with abnormal personality traits. They were not however distinguishable by other factors such as diagnosis, gender, age, marital status or accommodation.

Our study identified all patients who were admitted to acute psychiatric wards in Nottingham in 1990 three or more times. These patients were followed up four years later to look at outcome.

\section{The study}

There is little consensus on the definition of failed discharges with readmissions within one month to one year being included in different studies. 'Revolving door' patients have been defined as those having six or more admissions in a 12 month period (Rollin, 1965). Failed discharges and repeated admissions were usually precipitated by a recurrence of initial symptoms (Jones, 1991; Evans, 1992a,b). For the purposes of our study we decided to include all patients who had three admissions or more to acute wards in Nottingham in 1990. This would exclude some patients who had only one 'falled discharge'. Patients were identified from the Patient Administration System (PAS) and case notes were examined by the authors in 1992 and again in 1995. Information was collected on the number and duration of admissions, diagnosis, age, gender, service in 1990 and 1994 and location on follow-up. The services present in Nottingham 
Table 1. Demographic data

\begin{tabular}{lcl}
\hline Aos & Mole & Femalo \\
\hline $16-24$ & 2 & 3 \\
$25-34$ & 10 & 8 \\
$35-44$ & 3 & 4 \\
$45-54$ & 2 & 3 \\
$55-65$ & 2 & 5 \\
\hline
\end{tabular}

at the time are described elsewhere (Davies et al 1996). All admissions in Nottingham were discussed with a consultant or senior registrar (SR) and patients were often assessed by SRs before an out of hours admission. The threshold for admission was therefore relatively high but is probably similar to that of many inner-city areas where acute beds are scarce.

\section{Findings}

In 1990 there were 1160 admissions and 40391 occupied bed-days (there were 52925 available bed-days giving an occupancy of 76\%). Forty-two patients had three or more admissions in 1990. They accounted for 148 admissions (mean=3.5; range $=3-9)$ and occupled $5523(10.4 \%)$ available bed-days (mean=131; range=7-349).

The demographic data and primary and secondary diagnoses are given in Tables 1 and 2.

\section{Follow-up}

We managed to obtain information about 41 of the 42 patients four years later from the PAS. Two had been transferred to general services in other districts, three of the patients had died and one had been admitted to a Special Hospital following a homicide. Those remaining in contact with Nottingham services were distributed as follows: acute psychiatry, 27; rehabilitation and community care, 7; district forensic service, 1; total in service contact, 35 (83\%).

Only two were acute in-patients, three were in NHS continuing care or residential care. In the three years following the 1991 anniversary of their index admissions they had accounted for 98

Table 2. Primary and secondary dlagnoses

\begin{tabular}{llll}
\hline & & \multicolumn{2}{c}{ Secondary } \\
\cline { 3 - 4 } Diagnoses & Primay & PD & SM \\
\hline Bipolar & 13 & 2 & \\
Unipolar & 11 & 2 & 1 \\
Schizophrenia & 9 & & 2 \\
Schizoaffective & 5 & 1 & \\
Personality disorder (PD) & 2 & & \\
Substance misuse (SM) & 0 & & \\
No diagnosis & 2 & & \\
\hline
\end{tabular}

PD, personallity disorder; SM, substance misuse.
Table 3. Total number of admissions and occupled bed-days per year

\begin{tabular}{lllll}
\hline Admisetions & & \multicolumn{3}{c}{ Occupled bed-dory } \\
\cline { 4 - 6 } Year & Number & Acute & Other & $\begin{array}{l}3 \text { or mors } \\
\text { admiestoms }\end{array}$ \\
\hline $1991-2$ & 41 & 1402 & 1038 & 5 \\
$1992-3$ & 30 & 1284 & 746 & 1 \\
$1993-4$ & 27 & 645 & 425 & 3 \\
\hline
\end{tabular}

acute admissions (mean=2.33; range=0-20), 3331 acute occupled bed-days (OBDS) and 2209 non acute OBDS (rehabilitation, continuing care or elderly). The total number of admissions and occupied bed-days per year are given in Table 3. The rapid decrease in acute and other bed use over time is illustrated in Figure 1.

Outcomes fall into three groups: those who used services heavily in 1990 but have had no or very few admissions since; those who have continued to use acute in-patient services heavily: those with a poor outcome including prolonged hospitalisation, death or transfer to a high security facility.

Good outcome: 20 patients These patients used services little in the four years following their index admission in 1990, having less than three admissions and no admission of more than $\mathbf{9 0}$ days.

Continued heavy acute use: 10 patients This group included prolonged admissions or multiple admissions (one of these patients committed suicide shortly after the end of the four-year period):

$\begin{array}{ccc}\text { Patient } & \text { Occupied bed-days } & \text { Admissions } \\ 1 & 532 & 4 \\ 2 & 216 & 7 \\ 3 & 194 & 20 \\ 4 & 194 & 8 \\ 5 & 191 & 4 \\ 6 & 141 & 11 \\ 7 & 123 & 2 \\ 8 & 95 & 1 \\ 9 & 50 & 9 \\ 10 & 27 & 7\end{array}$

Poor outcome: 9 patients Three deaths were reported in this group: one of suicide, one open verdict and one from natural causes. All deaths occurred before March 1991 and had no multiple, prolonged or other admissions.

One patient had three further admissions, totalling 308 acute bed-days before discharge to a registered home where he committed the offence leading to his admission to a Special Hospital. 


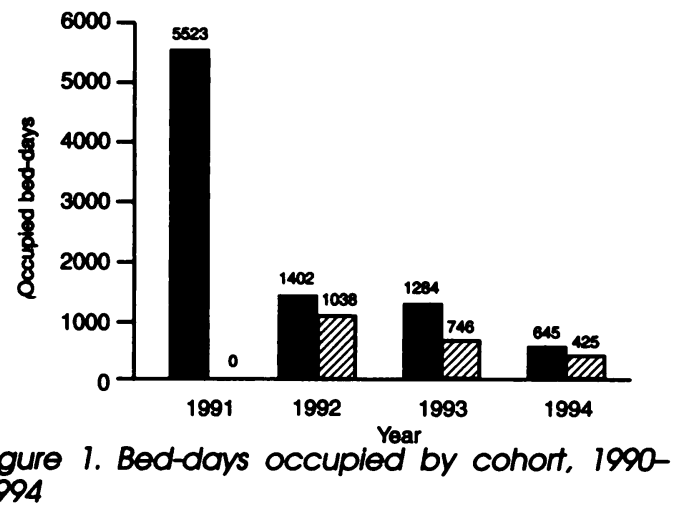

One patient was admitted to a continuing care facility and had been resident for 958 days at the end of the study. Four patients required prolonged rehabilitation admissions, occupying a total of 1218 bed-days (range 166-477). Almost all of the patients requiring prolonged in-patient stays in the rehabilitation service also required extended periods of acute admission before referral.

\section{Comment}

Although the patients in this study accounted for a large number of admissions and occupied beddays in 1990, the number of admissions and occupied bed-days has dropped since. The outcomes are extremely variable, ranging from stabilisation and discharge to homicide and suicide. Over half of the sample appeared to have had a 'bad year' in 1990 and has subsequently been maintained with out-patient treatment. Some patients were and still are suffering from severe mental illness and have required prolonged admissions since, either in acute wards or rehabilitation facilities. Only eight patients required more than three acute admissions in the next three years and five of these were hospitalised for a total of over six months in this period. It is worth noting that the district drug and alcohol service (with a dedicated admission facility) managed to prevent any patient with a primary diagnosis of substance misuse having three acute admissions in 1990. A secondary diagnosis of substance misuse or personality disorder did not appear to affect outcome. The patient admitted to a Special Hospital was however felt to exhibit schizoaffective disorder, personality disorder and solvent misuse. The three suicides and open verdicts in this group would give us one of the most productive populations to target for suicide risk. It is however hard to see what additional resources could have been offered to this high service use group to prevent these suicides.

Most of the study period predates Supervision Registers and the Care Programme Approach
(CPA) backed up by effective information systems. The number of 'revolving door' patients was very small, half had a good outcome and only one patient could not be traced at four-year follow-up. Even for those with a poor outcome it is not clear that different care would have made a great difference to outcome. We suspect that the CPA and Supervision Registers will add little or nothing in areas where there is effective community care. Areas where services are lacking CPA and Supervision Registers are unlikely to do other than identify deficits.

\section{Conclusion}

Although patients who require multiple admissions may cause frustration to the staff who care for them, a longer-term perspective may help us to be more understanding of their problems. Half of them are having a 'bad year' and will stabilise and do well. A quarter will do badly and require prolonged in-patient care or die. A further quarter will continue to use acute services heavily but only a tiny fraction will have frequent admissions without requiring prolonged in-patient stays on occasion.

\section{Acknowledgement}

We would like to thank Mark Smith, Medical Audit Assistant. Nottingham Healthcare NHS Trust, for identifying patients and bed occupancy figures from the Patient Administration System not a simple task.

\section{References}

COHEN, S. (1992) Patients repeatedly admitted to psychiatric wards (letter and reply). Psychiatric Bullettr, 16, 664.

- (1993) Patients repeatedly admitted to psychiatric wards (letter and reply). Psychiatric Bulletin, 17, 176.

DAVIES, S., PAYNE, S. \& JENKINS, J. (1996) Waiting for rehab? Psychiatric Bulletin, 20, 75-77.

EVANS, M., RiCE, D. \& RouTH, C. (1992a) Patlents repeatedly admitted to psychiatric wards. Psychiatric Bulletin. 16. 157-158.

-. - \& - (1992b) Patients repeatedly admitted to psychiatric wards. Psychiatric Bullettn, 16, 327-329.

JONES, E. (1991) Audit in psychiatry: 'failed discharges'. Psychiatric Bulletin, 16, 26-27.

MACMmLAN, D. (1958) Mental Health Services of Nottingham. Journal of Social Psychiatry, 4, 5-9.

RounN, H. R. (1965) Unprosecuted mentally abnormal offenders. British Medical Joumal, 1, 831-835.

Steffan Davies, Senior Registrar in Rehabilitation Psychiatry, Towers Hospttal, Leicester; and *Simon Payne, Consultant Rehabilitation Psychiatrist, Mapperley Hospital, Nottingham

*Correspondence 